\title{
Brinquedos e Brincadeiras na Educação em Ciências: Um Olhar para a Literatura da Área no Período de 1997 a 2017
}

\author{
Toys and Plays in Science Education: Looking at Literature \\ From the Field Between 1997 and 2017
}

\author{
Wagner da Cruz Seabra Eiras \\ Paulo Henrique Dias Menezes \\ Brasil \\ Cristhiane Carneiro Cunha Flôr \\ Brasil \\ Brasil
}

Apresentamos uma revisão de literatura dos artigos que tratam das atividades lúdicas, publicados nos anais dos Encontros de Pesquisa em Educação em Ciências (ENPEC) e na Revista Brasileira de Pesquisa em Educação em Ciências (RBPEC), no período de 1997 a 2017, para compreender como os brinquedos e as brincadeiras são tratados nessas publicações - particularmente, aqueles voltados para o Ensino Fundamental. Para selecionar os trabalhos, utilizamos mecanismos de busca eletrônica disponibilizados nos anais das edições do ENPEC e nas publicações da RBPEC por meio dos títulos e palavras-chave. Para analisar os dados, elaboramos uma categorização que classifica jogo como um objeto que possui regras rígidas, definidas a priori e independentes do sujeito que joga, e brinquedo como um objeto com regras mais flexíveis e elaboradas pelo sujeito que brinca. Nossos resultados mostram que a maioria dos trabalhos analisados foi classificada na modalidade jogo, indicando que os brinquedos e brincadeiras são ainda pouco explorados no contexto deste estudo. Além disso, os trabalhos que priorizam investigar o processo de elaboração e/ou participação em atividades lúdicas obtiveram informações mais detalhadas, que auxiliam na interpretação e compreensão do papel dessas atividades no ensino de Ciências. Entretanto, em alguns trabalhos, a atividade lúdica é considerada eficiente e suficiente por si só, e as informações obtidas por meio da investigação do processo de aplicação são usadas principalmente para confirmar a efetividade pedagógica do produto, indicando a necessidade de estudos mais aprofundados sobre a relação processo/produto nas pesquisas sobre brinquedos e brincadeiras na Educação em Ciências.

Palavras-chave: Jogos; Brinquedos; Educação em Ciências; Ensino Fundamental.

This paper is a review of literature on articles that address playing activities, published at the annual Brazilian Meetings on Research in Science Education (ENPEC) and in the Brazilian Journal of Research in Science Education (RBPEC), from 1997 to 2017. Our aim is to understand how toys and plays are covered in these publications - particularly 
those conducted in the context of Elementary School. In order to select the works, we used electronic search mechanisms available in the proceedings of the ENPEC and in the publications of RBPEC through titles and keywords. In order to analyze the data, we have developed a system of categories that classifies games as an object with strict rules, arranged beforehand, and regardless of the subject playing it, and toys as objects with more flexible rules, that are elaborated by the subject handling it. The results shows that the majority of the works analyzed are related to the game category, which means that games and plays are still underexplored in the context of this study. Additionally, the studies focused on investigating the process of preparation and/or performance of the playing activity gather more detailed information, which helps in the interpretation and understanding of the role of these activities in science teaching. However, in some studies, the play activity is considered efficient and sufficient on its own, and the information obtained from the process of investigation of the application process is used mainly to support the pedagogical effectiveness of the product, pointing the demand of further studies on the relationship between process and product in research on toys and plays in Science Education.

Keywords: Games; Toys; Science Education; Elementary Education.

\section{Brinquedos e brincadeiras como oportunidade de aprendizagem}

Os brinquedos e as brincadeiras ocupam uma posição de destaque na vida das crianças, sendo fundamentais para a sua formação psicológica e social. Segundo Vigotski (2008), a criança é movida pela atividade do brincar, a qual é um fator determinante no seu desenvolvimento, servindo como mecanismo de disparo e nutrição da imaginação. Uma criança pode jogar futebol e, ao mesmo tempo, descrever o drible desconcertante realizado em um adversário imaginário, imitando a voz de um narrador entusiasmado. Intercaladamente, a criança também expressa as reações de delírio da torcida fictícia diante daquela jogada, que resulta em gol nos últimos instantes de uma disputada decisão de campeonato. Depois do gol, a criança corre freneticamente, pulando e balançando os braços para a torcida, podendo até mesmo sentir o encontro acalorado com o restante do seu time. De forma semelhante, uma criança pode brincar de piloto de carros de corridas, sentada em uma cadeira, segurando com as suas mãos o volante de um carro imaginário, emitindo sons de aceleração, frenagem ou derrapagem de pneus ao fazer uma curva.

As crianças também utilizam objetos concretos para deixar fluir a sua imaginação. Um simples sabugo de milho pode virar um recém-nascido, permitindo vivenciar cenários apenas limitados pelo desejo de até onde sonhar. Conforme Walter Benjamin,

[...] ninguém é mais casto em relação aos materiais do que crianças: um simples pedacinho de madeira, uma pinha ou uma pedrinha reúnem na solidez, no monolitismo de sua matéria, uma exuberância das mais diferentes figuras. (Benjamin, 2009, p. 92). 
Autores como Vigotski, Leontiev e Elkonin desenvolveram importantes estudos sobre o desenvolvimento infantil, aprofundando a relação entre atividade e desenvolvimento para a formação do ser humano. Segundo Vigotski (2008),

[...] abrincadeira cria uma zona de desenvolvimento iminente na criança. Nabrincadeira, a criança está sempre acima da média da sua idade, acima de seu comportamento cotidiano; na brincadeira, é como se a criança estivesse numa altura equivalente a uma cabeça acima da sua própria altura. A brincadeira em forma condensada contém em si, como na mágica de uma lente de aumento, todas as tendências do desenvolvimento; ela parece tentar dar um salto acima do seu comportamento comum. (p. 15).

Hirsh-Pasek e Golinkoff (2008) afirmam que os jogos e brincadeiras exercem um papel central no desempenho escolar e que também podem contribuir na preparação das crianças para o mundo global, pois alimentam a colaboração, a comunicação, a criatividade e a confiança, entre outras competências e habilidades.

$\mathrm{Na}$ perspectiva da brincadeira como uma atividade fundamental no desenvolvimento infantil, as Diretrizes Curriculares Nacionais para a Educação Básica orientam os educadores brasileiros a explorar esse tipo de atividade desde os anos iniciais de escolarização, pois:

Brincar dá à criança oportunidade para imitar o conhecido e para construir o novo, conforme ela reconstrói o cenário necessário para que sua fantasia se aproxime ou se distancie da realidade vivida, assumindo personagens e transformando objetos pelo uso que deles faz. (MEC, 2013, p. 89).

Segundo as mesmas diretrizes, na perspectiva da continuidade do processo educativo,

[...] o Ensino Fundamental terá muito a ganhar se absorver da Educação Infantil a necessidade de recuperar o caráter lúdico da aprendizagem, particularmente entre as crianças de 6 (seis) a 10 (dez) anos que frequentam as suas classes, tornando as aulas menos repetitivas, mais prazerosas e desafiadoras e levando à participação ativa dos alunos. (MEC, 2013, p. 121).

$\mathrm{O}$ uso de brinquedos e brincadeiras no ensino e na aprendizagem de ciências vem despertando nosso interesse desde 2012, quando tivemos a oportunidade de atuar em um curso de capacitação de professores voltado para construção de brinquedos científicos. Posteriormente, tivemos a oportunidade de acompanhar os desdobramentos desse curso em sala de aula, o que resultou em um projeto de pesquisa com o objetivo de compreender como o processo de construção e de manipulação desses brinquedos pode contribuir para a promoção da Educação em Ciências nos anos iniciais do Ensino Fundamental. Este artigo apresenta uma revisão de literatura realizada para fins dessa pesquisa e tem o objetivo de compreender como os brinquedos e as brincadeiras são tratados nos estudos desenvolvidos na área de pesquisa em Educação em Ciências particularmente, aqueles voltados para o Ensino Fundamental - por meio da análise de artigos publicados nos anais dos Encontros de Pesquisa em Ensino de Ciências (ENPEC) 
e na Revista Brasileira de Pesquisa em Educação em Ciências (RBPEC).

Entendemos que os ENPEC e a RBPEC são representativos da comunidade acadêmica da área de pesquisa em Educação em Ciências no Brasil, pelo fato de ambos estarem vinculados à Associação Brasileira de Pesquisa em Educação em Ciências (ABRAPEC), que, de acordo com o artigo segundo de seu estatuto ${ }^{1}$, tem por finalidade:

[...] promover, incentivar, divulgar e socializar a pesquisa em Educação em Ciências, através de encontros de pesquisa, de formação para a pesquisa e publicações sobre pesquisa, bem como atuar como órgão representante da área junto a entidades nacionais e internacionais de educação, pesquisa e fomento inclusive as governamentais, sensibilizando-as e mobilizando-as para a importância de financiamento e apoio aos estudos pertinentes à Educação em Ciências e à formação de pessoal docente de alto nível.

Atualmente, a ABRAPEC congrega mais de 2.900 associados $^{2}$ nas diversas áreas das Ciências da Natureza. Por isso, consideramos que é a associação que melhor representa os pesquisadores da área de Educação em Ciências no Brasil.

\section{Jogo ou Brinquedo?}

$\mathrm{Na}$ fase preliminar desta pesquisa, a leitura exploratória dos artigos publicados nos anais das edições do ENPEC e na RBPEC que tratam de jogos e brincadeiras na Educação em Ciências mostrou que em vários desses trabalhos os termos jogo e brinquedo são utilizados de forma indistinta, parecendo referir-se a um mesmo objeto, o mesmo acontecendo em relação às ações de jogar e brincar. Por isso, optamos por iniciar este artigo com uma discussão sobre o uso desses termos.

Para Huizinga (2014), o termo jogo não é passível de uma definição exata e é tomado como um fenômeno cultural que acompanha e marca a cultura desde o início da civilização, pois “[...] a cultura surge como uma forma de jogo, que ela é, desde seus primeiros passos, como que 'jogada” (p.53). Para este autor, jogo tem origem na palavra latina ludus e abrange "[...] os jogos infantis, a recreação, as competições, as representações litúrgicas e teatrais e os jogos de azar.” (p. 41).

Huizinga (2014) afirma ainda que várias línguas europeias utilizam uma mesma palavra para designar tanto o ato de jogar quanto o de brincar, tais como spielen, to play, jouer, jugar, etc., sacrificando a exatidão na utilização desses termos. Outro exemplo é a palavra russa “играть” que também pode significar tanto brincar quanto jogar.

Walter Benjamin, em suas reflexões sobre criança, brinquedo e educação, utiliza o substantivo alemão spiele, que pode ser traduzido tanto como jogo, quanto como 1 Disponível em: http://abrapecnet.org.br/wordpress/wp-content/uploads/2013/10/estatuto-abrapec-registrado-nocarto\%CC\%81rio.pdf. Acesso em: 04 jan. 2018.

2 Disponível em:

http://www.abrapecnet.org.br/enpec/xi-enpec/anais/index.htm. Acesso em 05 jan. 2018.

3 Disponível em: https://www.google.com.br/

search?q=tradutor\&oq=traduo\&aqs=chrome.1.69i57j015.3798j0j8\&sourceid=chrome\&ie=UTF-8.

Acesso em: 13 jul. 2017. 
brinquedo. Além disso, Benjamin utiliza o verbo alemão spielen para significar brincar, jogar ou representar uma peça teatral, entre outras ações (Benjamim, 2009).

Kishimoto (2011), ao retratar a natureza e o significado do jogo e do brinquedo ao longo da história, mostra a polêmica que acompanha a apropriação desses termos na área da Educação. Segundo essa autora, "no Brasil, termos como jogo, brinquedo e brincadeira ainda são empregados de forma indistinta, demonstrando um nível baixo de conceituação deste campo." (p. 19), não sendo tarefa fácil definir e diferenciar jogo de brinquedo. Isso fica evidente na forma como a autora utiliza os termos brinquedo e jogo de acordo com o sentido que cada sociedade lhes atribui:

[...] dependendo do lugar e da época os jogos assumem significações distintas. Se o arco e a flecha hoje aparecem como brinquedos, em certas culturas indígenas representavam instrumentos para a arte da caça e da pesca. (Kishimoto, 2011, p.19, grifos nossos).

Essa dificuldade em diferenciar brinquedo de jogo também está presente no título de uma das seções do artigo de Kishimoto (2011), nomeada como: "Brinquedo educativo (jogo educativo)" (p. 40).

Apesar da dificuldade em diferenciar brinquedo de jogo, Kishimoto (2011) se apoia nos trabalhos de Brougère e Henriot, para enfatizar três níveis de diferenciação para o jogo: $1^{\circ}$ ) jogo como o resultado de um sistema linguístico que funciona dentro de um contexto social; $2^{\circ}$ ) jogo como um sistema de regras; e $3^{\circ}$ ) jogo como um objeto.

Em relação ao primeiro nível, o sentido de jogo depende da linguagem utilizada em determinado contexto social. Mesmo para um jogo específico como, por exemplo, o jogo de futebol, suas características são peculiares quando jogado por crianças em um campo de várzea, se compararmos com o mesmo jogo realizado por adultos em um campeonato oficial.

No segundo nível, um sistema de regras permite identificar no jogo um sistema sequencial que especifica a sua modalidade. Assim, um jogo de xadrez tem regras rígidas e explícitas previamente, diferentes das do jogo de damas, por exemplo.

Já o terceiro nível de diferenciação, refere-se a jogo enquanto objeto, isto é, um jogo pode ser facilmente caracterizado pelo objeto que o representa. No jogo de xadrez, por exemplo, são utilizadas peças dispostas e movimentadas de forma particular sobre um tabuleiro. No jogo de damas, apesar de ser possível utilizar o mesmo tabuleiro do jogo de xadrez, as peças têm características e movimentos bastante diferentes.

Agrupando o segundo e o terceiro nível de diferenciação propostos por Kishimoto (2011), o jogo pode ser caracterizado por um objeto que o representa e por um sistema de regras rígidas, explícitas previamente e centradas no objeto, independente de quem joga, isto é, um jogo de xadrez é igual para qualquer sujeito que o joga.

Apesar deobrinquedotambém dependerdeumsistemalinguísticoedeumcontexto social, esse difere do jogo por não possuir um sistema de regras, rígidas e explicitadas previamente, que organizam a sua utilização, ocasionando uma indeterminação quanto ao uso (Kishimoto, 2011). Uma boneca, por exemplo, dependendo da criança que brinca, pode ser considerada como filha, como mãe, como uma fada ou como uma 
bruxa, estabelecendo uma relação íntima com a criança devido à liberdade de utilização do brinquedo. Poder-se-ia argumentar que ao brinquedo também são atribuídas regras quando esse faz parte de uma brincadeira, pois a criança que brinca com a boneca como se fosse a sua filha estabelece regras que orientam suas ações, bem como as da boneca, coerentes com o enredo imaginado. Entretanto, diferindo do jogo, as regras atribuídas ao brinquedo são estabelecidas pela criança ao brincar, isto é, as regras são flexíveis e elaboradas pelo sujeito que brinca, não sendo, portanto, centradas no objeto, mas sim no sujeito. A mesma criança pode usar a mesma boneca em outro enredo de sua livre escolha, assim como outra criança tem a liberdade de considerar a mesma boneca como sendo a sua fada madrinha, ou qualquer outra representação desejada.

De acordo com Brougère (2001), o brinquedo enquanto objeto é impregnado dos mais variados significados, não possuindo uma função precisa, pois depende da interação da criança que protagoniza uma nova realidade, podendo diferir da função original para a qual foi produzido. Um copo e uma colher de plástico, por exemplo, podem remeter à brincadeira de construir castelos de areia, assim como folhas de papel podem ser usadas para brincar de construir aviões.

Do exposto, consideramos que brinquedos estimulam a representação e a expressão de imagens que evocam aspectos da realidade. Ao contrário, entendemos que jogos exigem, de modo explícito ou implícito, o desempenho de certas habilidades definidas por uma estrutura preexistente no próprio objeto e em suas regras.

Portanto, um brinquedo,

[...] enquanto objeto, é sempre suporte da brincadeira. É o estimulante material para fazer fluir o imaginário infantil. E a brincadeira? É a ação que a criança desempenha ao [...] mergulhar na ação lúdica. Pode-se dizer que é o lúdico em ação. Desta forma, brinquedo e brincadeira relacionam-se diretamente com a criança e não se confundem com o jogo. (Kishimoto, 2011, p.24, grifos da autora).

Em síntese, para o estudo aqui apresentado, classificamos como jogos objetos que possuem regras rígidas, definidas a priori e independentes do sujeito que joga. Por outro lado, consideramos como brinquedos objetos com regras mais flexíveis e elaboradas pelo sujeito que brinca, sujeito este imerso em um contexto sócio-histórico. Portanto, nessa perspectiva, consideramos que nos brinquedos as regras estão centradas no sujeito que brinca, enquanto que nos jogos as regras estão centradas nos objetos que os representam.

\section{Metodologia}

Uma revisão de literatura tem o objetivo de conhecer a produção já existente relacionada a um determinado tema para auxiliar na formulação de perguntas e indicar pontos polêmicos e lacunas no conhecimento relacionados ao tema que se pretende investigar (Creswell, 2014). Segundo Massoni (2017), a revisão bibliográfica consiste na exposição da produção intelectual já elaborada sobre o tema da pesquisa, sendo um dos itens fundamentais na pesquisa em Educação. Portanto, com este estudo, buscamos conhecer como a temática brinquedos e brincadeiras é tratada nas pesquisas em 
Educação em Ciências. Como fontes de dados utilizamos os artigos publicados nos anais dos Encontros Nacionais de Pesquisa em Educação em Ciências (ENPEC), realizados de 1997 a 2017 e nos dezessete volumes da Revista Brasileira de Pesquisa em Educação em Ciências (RBPEC), entre 2001 e 2017.

Para selecionar os trabalhos analisados neste estudo, utilizamos, inicialmente, os mecanismos de busca eletrônica disponibilizados nos anais das diversas edições do ENPEC e nas publicações da RBPEC para procurar no título ou nas palavras-chave dos artigos pelo menos um dos seguintes termos: lúdico, jogo ou brinquedo, bem como as variações em gênero, número ou classe gramatical desses termos. Com esse procedimento, numa primeira etapa, foram selecionados trabalhos de diferentes segmentos de ensino (Educação Básica, Ensino Superior e Educação de Jovens e Adultos).

Numa segunda etapa, esse material foi analisado por meio da leitura do resumo - ou do texto completo, quando necessário - para categorizar os artigos em relação ao nível de ensino e ao componente curricular da área das Ciências da Natureza para os quais o trabalho estava direcionado.

Posteriormente, centralizamos o estudo nos trabalhos obtidos na etapa anterior relativos ao Ensino Fundamental. Buscamos a correlação entre três categorias:

1) Tipo/modalidade de atividade lúdica (jogos, brinquedos, outras modalidades).

2) Foco principal da investigação (produto e/ou resultado da atividade lúdica ou processo de elaboração e/ou de aplicação da mesma).

3) Modalidade do estudo (Estudo teórico/Proposta de atividade lúdica).

A primeira categoria emergiu dos estudos de Benjamin (2009), Brougère (2001), Huizinga (2014) e Kishimoto (2011), os quais apresentamos na seção "Jogo ou Brinquedo?" e que apontam a diferenciação entre os termos jogo, brinquedo e brincadeira. A segunda categoria emergiu da análise exploratória dos trabalhos selecionados, na qual observamos que nos jogos ocorre maior valorização do resultado final do que nos acontecimentos durante o jogo, enquanto que nas brincadeiras esse resultado encontrase diluído no processo de aplicação da atividade, privilegiando-se o estudo do processo e não somente dos objetos (Vigotski, 2000). Feita essa correlação, aprofundamos a análise dos trabalhos categorizados na modalidade brinquedos em sua conexão com o foco no processo de investigação. A confiabilidade das análises foi verificada por meio da triangulação entre os autores.

\section{Ludicidade, jogos e brinquedos nos trabalhos do ENPEC e na RBPEC}

A tabela 1 mostra a distribuição quantitativa dos trabalhos (comunicações orais e pôsteres) publicados nos anais de todas as edições do ENPEC e daqueles relacionados aos termos lúdico, jogo ou brinquedo. 
Tabela 1. Distribuição quantitativa do total de trabalhos publicados nos anais de todas as edições do ENPEC e daqueles relacionados aos termos lúdico, jogo ou brinquedo

\begin{tabular}{ccccc}
\hline ENPEC & Ano & Total de Trabalhos & $\begin{array}{c}\text { Total de trabalhos } \\
\text { selecionados }\end{array}$ & $\%$ \\
\hline I & 1997 & 128 & 1 & 0,78 \\
\hline II & 1999 & 163 & - & 0 \\
\hline III & 2001 & 233 & 3 & 1,29 \\
\hline IV & 2003 & 451 & 3 & 0,67 \\
\hline V & 2005 & 739 & 15 & 2,03 \\
\hline VI & 2007 & 669 & 10 & 1,49 \\
\hline VII & 2009 & 799 & 10 & 1,25 \\
\hline VIII & 2011 & 1.235 & 22 & 1,78 \\
\hline IX & 2013 & 1.019 & 26 & 2,55 \\
\hline X & 2015 & 1.272 & 36 & 2,83 \\
\hline XI & 2017 & 1.335 & 39 & 2,92 \\
\hline \multicolumn{2}{c}{ TOTAL } & 8.043 & 165 & 2,05 \\
\hline
\end{tabular}

Fonte: Anais das edições do ENPEC, de 1997 a 2017.

Observando a tabela 1, percebe-se que houve um aumento significativo no número de trabalhos relacionados ao tema desta pesquisa a partir do VIII ENPEC. Todavia, podemos considerar que o percentual desses trabalhos $(2,05 \%)$ é pequeno em relação ao total de publicações desses Encontros. Isto pode indicar, guardada a multiplicidade de interesses da área de pesquisa em Educação em Ciências, que a ludicidade ainda é pouco explorada como objeto de estudo.

A tabela 2 mostra a distribuição do total de artigos publicados nos 17 volumes da RBPEC entre 2001 e 2017 e aqueles relacionados ao tema desta pesquisa.

Tabela 2. Distribuição do total de artigos publicados nos volumes de 1 a 17 da RBPEC e dos artigos relacionados ao tema desta pesquisa (continua)

\begin{tabular}{cccccccc}
\hline Volume & Ano & $\mathbf{N}^{\mathbf{1}} \mathbf{1}$ & $\mathbf{N}^{\mathbf{2}} \mathbf{2}$ & $\mathbf{N}^{\mathbf{3}} \mathbf{3}$ & Total de artigos & Total de artigos selecionados & $\mathbf{\%}$ \\
\hline 1 & 2001 & 12 & 12 & 12 & 36 & - & - \\
\hline 2 & 2002 & 6 & 8 & 6 & 20 & - & - \\
\hline 3 & 2003 & 8 & 4 & 4 & 16 & - & - \\
\hline 4 & 2004 & 8 & 8 & 8 & 24 & - & - \\
\hline 5 & 2005 & 6 & 4 & 5 & 15 & - & - \\
\hline 6 & 2006 & 4 & 4 & 4 & 12 & - & - \\
\hline 7 & 2007 & 4 & 4 & 4 & 12 & 2 & - \\
\hline 8 & 2008 & 6 & 6 & $6^{*}$ & 18 & - & 4,55 \\
\hline 9 & 2009 & 7 & 6 & 7 & 20 & 1 & \\
\hline 10 & 2010 & 7 & $7^{*}$ & 8 & 22 & & - \\
\hline
\end{tabular}

*Número onde está(ão) o(s) artigo(s) selecionado(s) daquele volume. 
Tabela 2. Distribuição do total de artigos publicados nos volumes de 1 a 17 da RBPEC e dos artigos relacionados ao tema desta pesquisa (continuação)

\begin{tabular}{|c|c|c|c|c|c|c|c|}
\hline Volume & Ano & $\mathrm{N}^{0} 1$ & $\mathrm{~N}^{\circ} 2$ & $\mathbf{N}^{0} 3$ & $\begin{array}{l}\text { Total de } \\
\text { artigos }\end{array}$ & Total de artigos selecionados & $\%$ \\
\hline 11 & 2011 & $10^{*}$ & 10 & 10 & 30 & 3 & 10,00 \\
\hline 12 & 2012 & 10 & 10 & 10 & 30 & - & - \\
\hline 13 & 2013 & 10 & 10 & 9 & 29 & - & - \\
\hline 14 & 2014 & 10 & $26^{*}$ & 8 & 44 & 1 & 2,27 \\
\hline 15 & 2015 & 10 & $10^{*}$ & 10 & 30 & 1 & 3,33 \\
\hline 16 & 2016 & 16 & 12 & 10 & 38 & - & - \\
\hline 17 & 2017 & $13^{*}$ & 14 & 14 & 41 & 1 & 2,44 \\
\hline \multicolumn{5}{|c|}{ Total } & 437 & 9 & 2,06 \\
\hline
\end{tabular}

*Número onde está(ão) o(s) artigo(s) selecionado(s) daquele volume.

Fonte: publicações da RBPEC, de 2001 a 2017.

Dos 437 artigos publicados na RBPEC no período de 2001 a 2017, apenas 9 estão relacionados aos termos desta pesquisa (2,06\%), mantendo basicamente a mesma proporção de artigos publicados nos ENPEC. Tal dado corrobora a ideia de que as atividades lúdicas têm sido pouco exploradas na área de pesquisa em Educação em Ciências.

\section{Síntese da quantidade de trabalhos e artigos selecionados por nível de ensino.}

A tabela 3 mostra a distribuição quantitativa dos trabalhos e artigos selecionados dos ENPEC e da RBPEC por nível de ensino:

Tabela 3. Distribuição quantitativa dos trabalhos selecionados nos níveis de ensino.

\begin{tabular}{lc}
\hline Nível de ensino & Trabalhos selecionados \\
\hline Educação Infantil & 5 \\
\hline Ensino Fundamental & 63 \\
\hline Ensino Médio & 66 \\
\hline Ensino Superior e Pós-Graduação & 23 \\
\hline Educação de Jovens e Adultos & 2 \\
\hline Sem especificação & 15 \\
\hline Total & 174 \\
\hline
\end{tabular}

Fonte: Anais das edições do ENPEC, de 1997 a 2017 e publicações da RBPEC, de 2001 a 2017.

Para compreender como os trabalhos selecionados estão distribuídos em relação aos componentes curriculares da área das Ciências da Natureza, construímos a tabela 4. Nesta tabela, os trabalhos de Ciências são considerados no campo da Biologia devido a 
maioria deles estar relacionado a esse componente curricular.

Tabela 4. Distribuição dos trabalhos selecionados de acordo com as fontes de pesquisa, com os níveis de ensino: Educação Infantil (EI), Ensino Fundamental (EF), Ensino Médio (EM), Ensino Superior e Pós-graduação (ES), Educação de Jovens e Adultos (EJA) e sem especificação (SE), e em relação aos componentes curriculares da área das Ciências da Natureza

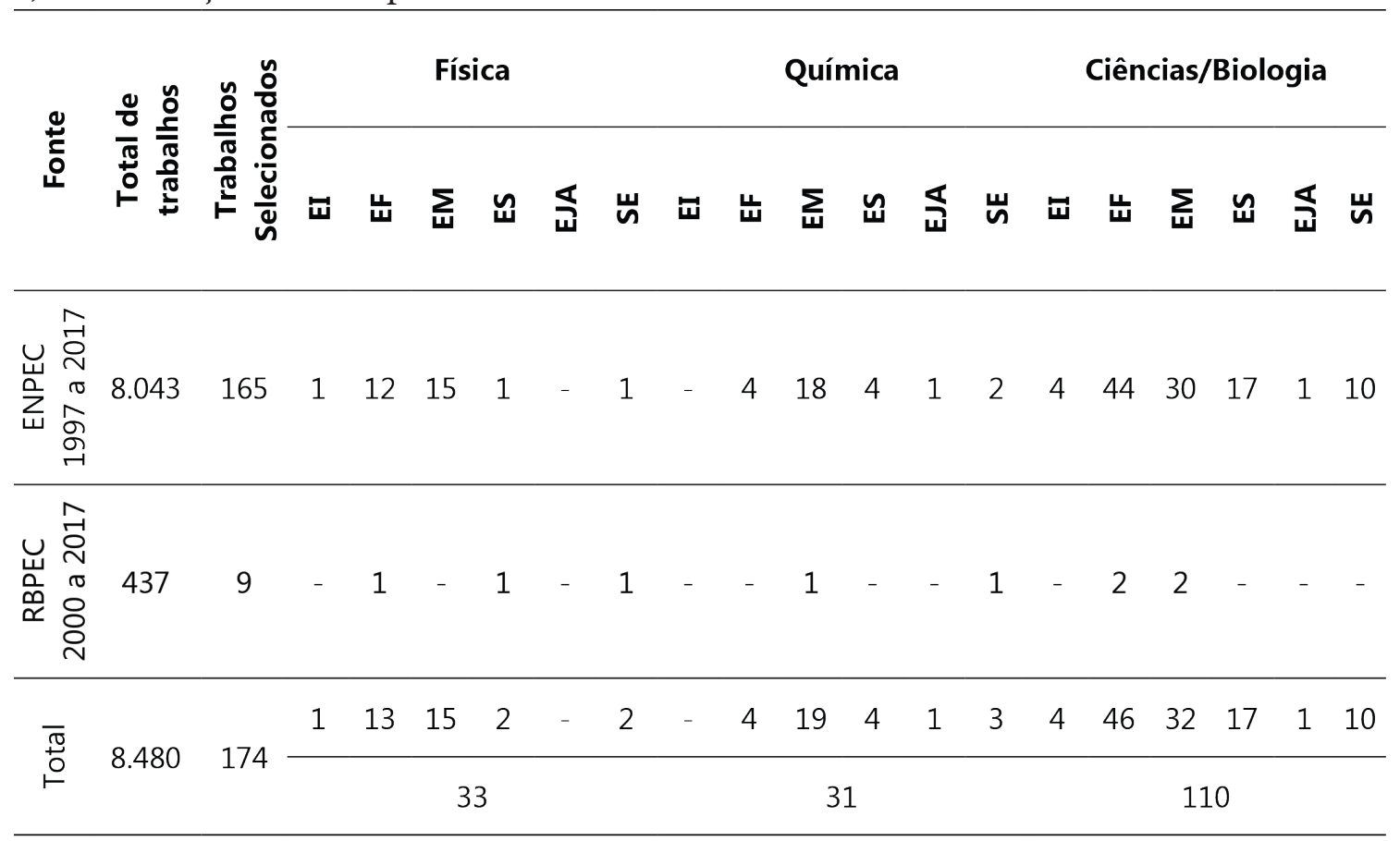

Fonte: Anais das edições do ENPEC, de 1997 a 2017 e publicações da RBPEC, de 2001 a 2017.

O escopo da RBPEC é publicar artigos originais, porém, esses podem ser originários de trabalhos apresentados no ENPEC, desde que o artigo seja claramente uma expansão do trabalho inicial, evitando-se o autoplágio. Apesar disso, observamos que, entre os artigos selecionados para esta pesquisa, apenas dois apresentaram correlação entre as publicações na RBPEC (Ferreira, \& Meirelles, 2015; Oliveira, Soares, Cunha, \& Monteiro, 2008) e os trabalhos apresentados em algum ENPEC (Ferreira, \& Meirelles, 2007; Oliveira \& Monteiro, 2005). Isso significa que praticamente não há duplicidade entre os trabalhos selecionados nas duas fontes. Apesar de não ser objetivo deste artigo, essa constatação faz suscitar outras questões: Por que os autores de trabalhos apresentados em congressos não se ocupam em incrementá-los para publicá-los em revistas científicas? Os trabalhos apresentados nos ENPEC originam artigos publicados em revistas científicas? Quais seriam essas revistas?

A distribuição apresentada na tabela 4 indica um maior número de trabalhos relacionados ao componente curricular de Ciências/Biologia (110 trabalhos), sendo 46 deles direcionados ao Ensino Fundamental, de um total de 63 selecionados nesse nível de ensino (conforme a tabela 3). Dos outros 17 trabalhos, 13 são referentes à Física e 4 à Química. Para compreender a razão do maior número de trabalhos vinculados ao 
componente curricular de Ciências/Biologia, procedemos à distribuição quantitativa desses trabalhos em relação às fases do Ensino Fundamental: anos iniciais (do $1^{\circ}$ ao $5^{\circ}$ ano) e anos finais (do $6^{\circ}$ ao $9^{\circ}$ ano), indicada na tabela 5 .

Tabela 5. Distribuição quantitativa dos trabalhos selecionados em relação aos componentes curriculares e às fases do Ensino Fundamental: anos iniciais (AI), anos finais (AF) e sem especificação (SE)

\begin{tabular}{lcccc}
\hline Componente curricular & AI & AF & SE & Total \\
\hline Física & 6 & 5 & 2 & 13 \\
\hline Química & - & 4 & - & 4 \\
\hline Ciências/Biologia & 5 & 28 & 13 & 46 \\
\hline Total & 11 & 37 & 15 & 63 \\
\hline
\end{tabular}

Fonte: Anais das edições do ENPEC, de 1997 a 2017 e publicações da RBPEC, de 2001 a 2017

Nessa distribuição, observa-se uma maior concentração de trabalhos de Ciências/Biologia nos anos finais do Ensino Fundamental. Nesse segmento de ensino, os professores de Ciências são, em geral, licenciados em Biologia (Chaves, \& Shellard, 2005), o que pode explicar, em tese, o maior número de trabalhos desse componente curricular no Ensino Fundamental. Por outro lado, o baixo número de trabalhos de Ciências/Biologia voltados para os anos iniciais (5) pode ser decorrente da formação em Pedagogia dos professores que lecionam Ciências nesta fase do Ensino Fundamental e, consequentemente, têm pouca ou nenhuma vinculação a uma associação como a ABRAPEC.

Já os seis trabalhos voltados para Física nos anos iniciais do Ensino Fundamental (Eiras, \& Menezes, 2015; Figueiredo et al., 2011; Magno, \& Almeida, 2015; Menezes, Mattoso, \& Miranda, 2015; Santos, Magalhães, \& Gois, 2009; Verazto et al., 2005) parecem sinalizar uma maior preocupação da comunidade acadêmica em abordar os conceitos físicos desde o início dessa etapa escolar, configurando um campo de investigação emergente.

A partir deste ponto apresentamos a análise apenas dos trabalhos referentes ao Ensino Fundamental, indicados na tabela 5.

\section{Jogos e brinquedos nos trabalhos das edições do ENPEC e nos artigos da RBPEC referentes ao Ensino Fundamental}

Como exposto na segunda seção deste artigo, consideramos quejogos diferenciamse de brinquedos pelo fato de os primeiros proporcionarem uma atividade lúdica com regras rígidas, definidas a priori e independentes do sujeito que joga. Portanto, para fins de classificação dos trabalhos selecionados, considera-se que a atividade lúdica realizada no formato de jogos pressupõe o uso de regras que estão centradas no objeto que o representa.

Por sua vez, brinquedos proporcionam atividades com regras flexíveis e elaboradas 
pelo sujeito que brinca. Nessa perspectiva, consideramos que na atividade realizada com brinquedos, isto é, numa brincadeira, as regras estão centradas no sujeito que brinca, sujeito esse considerado sócio-histórico, influenciando e sendo influenciado pelo meio no qual está inserido.

Portanto, apesar de entendermos que o ato de jogar também pode ser considerado como uma brincadeira, assim como um brinquedo também pode ser utilizado para a realização de um jogo, optamos por categorizar os trabalhos selecionados referentes ao Ensino Fundamental considerando que a função primária dos brinquedos é gerar uma brincadeira com regras flexíveis e centradas naquele que brinca, enquanto que a função primária dos jogos é possibilitar o ato de jogar com regras rígidas e centradas no objeto, instrumento do jogo. Com base nessa categorização classificamos esses trabalhos como jogos, brinquedos ou outras modalidades, tais como aula-passeio, história em quadrinhos, apresentação teatral, etc. ${ }^{4}$. A tabela 6 apresenta a síntese dessa classificação.

Tabela 6. Distribuição dos trabalhos selecionados do Ensino Fundamental em relação às modalidades das atividades lúdicas (jogos, brinquedos ou outras modalidades), de acordo com os componentes curriculares.

\begin{tabular}{lccc}
\hline Componente curricular & Jogos & Brinquedos & Outras modalidades \\
\hline Física & 4 & 6 & 3 \\
\hline Química & 2 & - & 2 \\
\hline Ciências/Biologia & 35 & 1 & 10 \\
\hline Total & 41 & 7 & 15 \\
\hline
\end{tabular}

Fonte: Anais das edições do ENPEC, de 1997 a 2017 e publicações da RBPEC, de 2001 a 2017.

Com base nas categorias que estabelecemos, a maioria dos trabalhos foi classificada na modalidade jogos (41), seguidos de 15 em outras modalidades e apenas 7 na modalidade brinquedos. A partir dos parâmetros por nós estabelecidos, esse resultado sinaliza certa carência de pesquisas relacionadas aos brinquedos e brincadeiras na Educação em Ciências no Ensino Fundamental.

Conforme descrito na metodologia, para estudarmos a correlação entre o tipo de modalidade do trabalho e o foco principal de investigação, analisamos a metodologia de pesquisa, os resultados e as conclusões de cada trabalho para categorizá-los de acordo com o seu foco principal de estudo: investigar o produto gerado pela atividade lúdica ${ }^{5}$ u investigar o processo de elaboração e/ou de aplicação da atividade. Também elegemos uma categoria para englobar trabalhos que propõem alguma atividade lúdica ou que apresentam um estudo teórico sobre a ludicidade na Educação em Ciências. A tabela 7 apresenta os resultados dessa categorização.

4 No campo "Outras modalidades" também são considerados os trabalhos que não especificam a modalidade da atividade, sendo nomeados de atividade lúdica.

5 Objeto produzido na atividade lúdica (jogo, brinquedo, etc.) ou resultado de teste, questionário, entrevista, ou outro instrumento de avaliação, realizado antes e/ou após a realização da atividade lúdica. 
Tabela 7. Distribuição dos trabalhos selecionados do Ensino Fundamental em relação à modalidade e ao foco principal do trabalho.

\begin{tabular}{lccc}
\hline \multirow{2}{*}{ Modalidade } & \multicolumn{3}{c}{ Foco principal do trabalho } \\
\cline { 2 - 4 } & Produto & Processo & Proposta de atividade lúdica/ Estudo teórico \\
\hline Jogos & 23 & 13 & 5 \\
\hline Brinquedos & 1 & 4 & 2 \\
\hline Outras & 2 & 9 & 4 \\
\hline Total & 26 & 26 & 11 \\
\hline
\end{tabular}

Fonte: Anais das edições do ENPEC, de 1997 a 2017 e publicações da RBPEC, de 2001 a 2017.

A maioria dos trabalhos com foco no produto está na modalidade jogos (23). Esses trabalhos focalizam suas análises em produtos gerados da aplicação de jogos que, de forma geral, são desenvolvidos a partir de regras preestabelecidas para se chegar a um objetivo previamente definido. Nesses trabalhos, a investigação é realizada a partir de diversos instrumentos metodológicos ${ }^{6}$, tais como: pré e pós-teste (Almeida, Lopes, \& Dal-Farra, 2013; Fraga, Pery, \& Nunes, 2011; Kraetzig, \& Amorim, 2001; Santana, \& Rezende, 2007); atividade de livre associação realizada antes e após o jogo (Rosse, Spiegel, \& Luz, 2015; Santos, Luz, \& Oliveira, 2013); questionários (Fontoura, Lima, Santos, \& Pereira, 2009; Herrera, 2015; Nicácio, Almeida, \& Correia, 2017; Oliveira, Carvalho, \& Góes, 2011; Ramos, Tanaka, \& Anic, 2013; Silva, Silva, Mise, Dores, \& Araújo, 2011); questionários e pré e pós-teste (Matos, Giusta, \& Sabino, 2007); entrevistas (Anjos, \& Serrano, 2017; Freitas, \& Andrade, 2017; Santos, \& Oliveira, 2015); textos críticos (Silva, \& Mesquita, 2015) e fichas (Garcia, \& Nascimento, 2017; Gondim, \& Machado, 2015).

Apesar de esses trabalhos não explicitarem o objetivo de analisar o processo de aplicação da atividade lúdica, alguns relatam observações que foram realizadas durante a aplicação do jogo, de forma breve, tais como: “[...] o clima de descontração era permanente no decorrer da atividade." (Ramos, Tanaka, \& Anic, 2013, p. 6); "Durante a aplicação do jogo 'Na Trilha dos Nutrientes', percebemos o interesse dos alunos pelo tema em questão" (Santos, Luz, \& Oliveira, 2013, p. 7); “[...] o jogo aumenta a atenção e o interesse dos alunos.” (Almeida, Lopes, \& Dal-Farra, 2013, p. 6); “[...] percebemos o interesse dos alunos pelo tema em questão e a interação entre os participantes para discutir as questões propostas." (Santos, \& Oliveira, 2015, p. 7); “[...] durante a aplicação do jogo, era perceptível o interesse entre os participantes." (Garcia, \& Nascimento, 2017, p. 5).

Na modalidade brinquedo, Menezes, Mattoso e Miranda (2015) não se preocuparam em descrever o processo de construção de brinquedos científicos por alunos do $5^{\circ}$ ano do Ensino Fundamental, mas relatam que o prazer que a atividade proporciona aos alunos é um fator que merece destaque. Além disso, os autores comentam que os relatos da professora regente da turma "[...] indicam mudanças significativas no interesse e na motivação dos alunos desde o início do projeto" (p. 7).

6 Nomeados pelos autores. 
Esses apontamentos indicam que, mesmo nos estudos em que o foco está no produto da atividade lúdica, os autores observaram que essas atividades também estimulam o interesse, a participação e a interação entre os alunos, habilidades estas fundamentais para o aprendizado (Vigotski, 2000).

Outros autores, apesar de indicarem estar atentos à observação do processo de desenvolvimento da atividade lúdica, não exploram essas habilidades com muita profundidade. Fraga, Pery e Nunes (2011), por exemplo, apresentam um estudo sobre a aplicação de um jogo para o desenvolvimento do conceito de velocidade média em alunos do $9^{\circ}$ ano do Ensino Fundamental no qual utilizaram como metodologia a pesquisa de campo para coletar dados diretamente no local em que o fenômeno ocorreu. Entretanto, essa pesquisa de campo é pouco explorada na descrição dos resultados e nas discussões que apresentam no texto, indicando apenas que durante "[...] a aplicação da atividade e pesquisa pôde-se perceber a curiosidade, satisfação, envolvimento e interesse por parte dos estudantes em participarem ativamente de todo o processo" (p. 4). Da mesma forma, Gondin e Machado (2015) discutem a construção de um jogo didático elaborado por nove professores do $6^{\circ}$ e $9^{\circ}$ anos do Ensino Fundamental e os saberes envolvidos no material produzido. Nesse caso, as autoras informam que as atividades desenvolvidas foram gravadas e transcritas, porém a análise apresentada no trabalho foi baseada apenas nas fichas do jogo que foram elaboradas pelos professores. O mesmo acontece com Freitas e Andrade (2017) que também relatam que os dados da pesquisa sobre a utilização de um jogo no ensino de Física foram obtidos por meio de observações e de entrevistas. Entretanto, somente as entrevistas são analisadas. De certa forma, isso mostra quais dados poderiam trazer à tona sutilezas do processo de aplicação dessas atividades lúdicas e que não são contemplados nas análises realizadas.

De acordo com a classificação que adotamos para compor a tabela 7, 26 trabalhos indicam ter o foco da análise na investigação do processo de elaboração e/ou de aplicação da atividade lúdica. Ainda na categoria jogos, Ferreira e Meirelles (2007), por exemplo, apresentam e discutem o processo de elaboração de uma atividade lúdica relacionada ao tema água e saúde, construída por alunos do $6^{\circ}$ ano do Ensino Fundamental, com base na metodologia participativa. Os dados da pesquisa foram obtidos de entrevistas com os alunos e da observação cuidadosa do processo de elaboração do jogo. A relevância da investigação do processo de elaboração da atividade lúdica é evidenciada em um trecho da descrição da atividade desenvolvida pelos alunos:

Esta fase foi muito importante para o crescimento de interesse pelo material e inserção de conteúdo, pois a cada frase criada, a cada sugestão de modificação, a cada inserção de algo novo, os alunos se identificavam mais com o material, que parecia simular suas representações em relação ao conteúdo. (Ferreira, \& Meirelles, 2007, p.5).

Nesse trabalho, as autoras concluem que

O processo de elaboração da atividade "Jogando Água" mostrou que a participação, a valorização dos saberes iniciais e construídos pelos alunos contribui para o empenho e inclusão de conteúdo no material e construção do conhecimento. Além disso, o 
processo de elaboração do material fez com que os alunos se sentissem autores reais de seus trabalhos e de seus aprendizados, o que é fundamental na formação de pessoas. (Ferreira, \& Meirelles, 2007, p. 7).

Em outro trabalho, Ferreira e Meirelles (2015) mostram como a investigação do processo possibilita compreender, em maior profundidade, o envolvimento dos alunos com a aprendizagem, decorrente da elaboração de materiais lúdicos relacionados à saúde, orientados por uma metodologia participativa que

[...] levou à reflexão de saberes anteriores, estimulando sentimentos importantes no processo de ensino-aprendizagem, como o orgulho e vontade de aprender, e valorizando os alunos como sujeitos que pretenderam ajudar no aprendizado de outras pessoas em direção à promoção da saúde. (Ferreira, \& Meirelles, 2015, p. 289).

Cavalcanti, Guimarães, Barbosa e Sério (2013) também evidenciam a relevância em investigar o processo de aplicação de um jogo didático que aborda temas relacionados à Física e à Química com alunos do $9^{\circ}$ ano do Ensino Fundamental. $\mathrm{Na}$ análise dos dados, as autoras relatam que, durante a aplicação do jogo, os alunos “[...] puderam discutir os conceitos e decidirem (sic) em conjunto a favor de uma resposta. Não houve casos em que a falta momentânea de consenso fosse um problema e não houve desavenças durante a aplicação do jogo" (p. 6-7).

De forma geral, os achados nos trabalhos cujo foco principal de investigação é o processo de elaboração e/ou aplicação da atividade lúdica estão relacionados às ações e reações dos sujeitos pesquisados durante a atividade. Como exemplo, podemos citar o relato de Souza, Yoshimura, Patrícia e Testoni (2017) ao analisar a utilização de elementos de perícia criminal no ensino de Ciências:

Após a entrega do croqui e explicação da proposta, percebemos uma participação inicial bastante tímida e retraída, até o momento em que a interação dos alunos com a atividade proposta começou a acontecer. Neste momento, surgem as primeiras perguntas e indagações (hipóteses formuladas). (Souza et al., 2017, p. 7).

Damasceno e Marin (2017) também se preocuparam em investigar o processo de realização de um jogo associado ao tema Citologia para identificar elementos que motivam os alunos a se envolverem e participarem do jogo, além de outros aspectos. Segundo essas autoras,

Durante as aulas de citologia os alunos puderam se expressar, correr e rir ao mesmo tempo em que aprimoravam seus conhecimentos sobre citologia. Além disso, o jogo facilitou a relação entre os alunos, fazendo com que eles aprendessem a trabalhar em equipe e saber que todos têm capacidade e que respeito é fundamental para se conquistar os objetivos almejados. (Damasceno, \& Marin, 2017, p. 6).

Da mesma forma, Souza e Rizatti (2017) analisam as interações discursivas entre os estudantes durante a realização de um jogo. Segundo esses autores, durante o desenvolvimento do jogo, as falas dos estudantes puderam ser categorizadas em cinco conversas de aprendizagem: perceptiva, conceitual, conectiva, estratégica e afetiva. 
Portanto, pode-se observar que os trabalhos que também se preocupam em investigar o processo de elaboração e/ou de aplicação da atividade lúdica relatam achados difíceis de serem percebidos quando se olha apenas para o produto gerado pela atividade.

Dos onze trabalhos classificados na categoria "Proposta de atividade/Estudo teórico", quatro são referentes a propostas de jogos, seis são referentes a estudos teóricos sobre a ludicidade na Educação em Ciências e um é referente à proposta de brinquedos.

$\mathrm{Na}$ subcategoria referente a trabalhos que apresentam propostas de jogos, Joucoski et al. (2011) apresentam a construção de jogos de cartas colecionáveis como instrumentos que contribuem para a aprendizagem em Ciências; Souza e Nascimento (2005) descrevem a elaboração e produção de jogos pedagógicos ecológicos para o ensino de Ciências, Ecologia e Educação Ambiental; Menezes, Santos, Silva, Magalhães e Xavier (2007) apresentam algumas sugestões de utilização de quebra-cabeças com palitos de fósforos no ensino de Matemática e de Ciências; e Oliveira (2007) apresenta um jogo sobre a natureza do conhecimento científico para ser utilizado como atividade didática no ensino de Ciências.

Na subcategoria estudos teóricos, Moreira, Abreu, Leal e Ramos (2011) analisam artigos relacionados aos jogos simbólicos e discutem as contribuições desses jogos para o processo de ensino e aprendizagem das Ciências; Bardi e Campos (2005) verificam como professores dos anos iniciais do Ensino Fundamental trabalham educação sexual com seus alunos; Oda (2013), apresenta um estudo exploratório de documentos e letras de música do compositor pernambucano Chico Science e argumenta sobre a pertinência de utilização de elementos da obra do músico para a promoção de um ensino de ciências contextualizado, interdisciplinar e transformador; Faria e Shuvartz (2011) analisam o projeto "A escola vai ao bosque Auguste Saint-Hilaire" como um espaço de educação não formal; e Messeder e Moradillo (2013) mostram como a ludicidade contribui para o desenvolvimento do indivíduo e para o ensino e a aprendizagem dos conceitos científicos.

\section{Trabalhos selecionados na modalidade brinquedos}

Dos 63 trabalhos selecionados do Ensino Fundamental, apenas 7 foram classificados na modalidade brinquedos. Apesar do pequeno número de trabalhos nessa modalidade (Almeida, Barbosa, \& Medeiros, 1997; Eiras, \& Menezes, 2015; Eiras, 2017; Figueiredo et al., 2011; Magno, \& Almeida, 2015; Menezes, Mattoso, \& Miranda, 2015; Veraszto et al., 2005), as publicações realizadas no decorrer dos anos sinalizam para um campo de investigação emergente.

Almeida, Barbosa e Medeiros (1997) apresentam brinquedos relacionados aos fenômenos óticos que envolvem em seu funcionamento uma série de elementos de curiosidade e mistério a fim de despertar o interesse das crianças no aprendizado de conceitos físicos presentes nos brinquedos. Eiras (2017) apresenta uma revisão bibliográfica das comunicações orais apresentadas nas edições do ENPEC, de 1997 a 
2015, para compreender como a comunidade acadêmica relaciona a brincadeira com a Educação em Ciências no Ensino Fundamental. Menezes, Mattoso e Miranda (2015) analisam os registros produzidos por alunos do $5^{\circ}$ ano do Ensino Fundamental, após a construção de brinquedos científicos nas aulas de Ciências, concluindo que "[...] os brinquedos ajudam a estimular a imaginação e a capacidade das crianças, o que pode afetar diretamente o interesse e a motivação dos alunos para o estudo dos conceitos científicos." (p. 1).

Conforme a tabela 7, quatro trabalhos classificados na modalidade brinquedos focalizam a investigação do processo de aplicação da atividade lúdica. Veraszto et al. (2005), por exemplo, mostram o desenvolvimento, a aplicação e a análise dos resultados de atividades tecnológicas, lúdicas e contextualizadas a partir das quais alunos dos anos iniciais do Ensino Fundamental buscaram soluções práticas para problemas cotidianos. Segundo os autores, com a utilização da tecnologia no processo de ensino-aprendizagem

“[...] é possível proporcionar aos alunos o desenvolvimento da criatividade, o seu aprimoramento cultural, trabalhando a formação de uma auto-imagem positiva de forma que ele seja capaz de resolver problemas práticos que possibilitem melhorar as condições de vida do ser humano." (Veraszto et al., 2005, p. 11).

Figueiredo et al. (2011) analisam e descrevem o projeto Brinca Ciência, no qual crianças que cursavam o $4^{\circ}$ e o $5^{\circ}$ ano do Ensino Fundamental ganharam materiais para construir brinquedos científicos. A avaliação do projeto foi realizada através da análise da produção escrita dos alunos, de suas falas e atitudes. Para tanto, o professor e o formador ${ }^{7}$ registraram suas observações durante a realização das atividades. Segundo os autores, no decorrer do projeto, “[...] os alunos apresentam evidências de desenvolvimento de habilidades cognitivas observáveis no aprimorar dos discursos presentes em relatos orais e escritos.” (p. 9). Em relação aos professores que participam do projeto, os autores afirmam que a maioria deles

[...] mantém uma postura participativa durante a realização das oficinas, quer seja auxiliando os alunos na confecção, quer seja interagindo com os formadores, ou até mesmo incentivando os alunos a fazer questionamentos e transpor o que aprenderam na forma de registro. (Figueiredo et al., p. 10).

Eiras e Menezes (2015) analisaram a transposição de uma metodologia de ensino de Ciências baseada na construção de um brinquedo científico denominado "Joaninha Teimosa" para a realidade da sala de aula a partir de notas de campo, entrevista com a professora e análise dos materiais produzidos pelos alunos. $\mathrm{O}$ acompanhamento da transposição da metodologia de ensino para a sala de aula proporcionou a coleta de informações importantes para a compreensão desse processo, que não seriam perceptíveis somente pela entrevista com a professora ou pela análise dos materiais produzidos pelos seus alunos. Os trechos abaixo, relacionados a um dos episódios, exemplificam esta afirmação:

7 Profissional especializado que auxilia as crianças na construção dos brinquedos científicos. 
Os alunos estavam eufóricos e curiosos para montar o brinquedo, mas a professora os orientou para iniciarem a leitura compartilhada, em voz alta, do livro de atividades [...] Depois disso, cada aluno montou sua joaninha e, com orgulho, mostravam sua construção para os colegas e para a professora. Muitos alunos ficaram entusiasmados com o fato de a Joaninha Teimosa retomar imediatamente sua posição de equilíbrio, quando colocada de cabeça para baixo [...]. Essa observação gerou uma alvoroçada busca pelo porquê daquela insistência do brinquedo. (Eiras, \& Menezes, 2015, p.5).

Magno e Almeida (2015) apresentam uma pesquisa sobre a potencialidade de associação entre a ludicidade e a abordagem Ciência, Tecnologia e Sociedade (CTS) no processo de ensino-aprendizagem de Ciências na Educação Básica. As autoras descrevem as atividades desenvolvidas com estudantes de turmas multisseriadas do $3^{\circ}$ ao $5^{\circ}$ ano do Ensino Fundamental de uma comunidade ribeirinha da Amazônia. Nessa descrição fica evidente que a participação dos alunos não obedeceu a um roteiro rígido, previamente determinado, mostrando que um pesquisador deve estar atento a eventos inesperados quando se propõe a investigar o processo de realização de uma atividade.

Durante a construção e teste dos barquinhos eles comentaram a diferença entre uma embarcação movida a diesel e a gasolina, daquela que utiliza o remo. Iniciaram uma discussão sobre os valores econômicos de cada embarcação e de quem tinha ou não barcos na comunidade. (Magno, \& Almeida, 2015, p. 5).

Nos relatos apresentados, as crianças estavam discutindo fatos em contextos reais de sua comunidade e se viam como parte deste ambiente e das controvérsias geradas pelo modelo de sociedade em que vivemos. (Magno, \& Almeida, 2015, p. 5).

Nas conclusões do trabalho, as autoras mostram a relevância da investigação do processo de aplicação da atividade lúdica, indicando terem percebido que "[...] as atividades propostas favoreceram a criatividade, o raciocínio, a argumentação e a interação entre os envolvidos, para a compreensão dos problemas sociopolíticos e ambientais da contemporaneidade." (Magno, \& Almeida, 2015, p. 7).

Consideramos que o fato de a maioria dos trabalhos selecionados na modalidade brinquedos focalizar a investigação do processo de aplicação da atividade está relacionado à liberdade de ação que o brinquedo possibilita aos sujeitos que brincam, o que permite uma compreensão mais detalhada da atividade lúdica.

\section{Considerações finais}

$\mathrm{Na}$ revisão de literatura dos trabalhos publicados nos anais das edições do ENPEC, de 1997 a 2017, e na RBPEC, de 2000 a 2017, realizada para fins deste artigo, constatamos que estudos que tratam de jogos, brinquedos e brincadeiras na Educação em Ciências, representam um percentual muito pequeno das pesquisas que vêm sendo publicadas nesses dois veículos de divulgação. Guardadas as especificidades dos critérios adotados nesta revisão, isso pode indicar uma exploração ainda incipiente de estudos sobre atividades lúdicas na Educação em Ciências, particularmente, aqueles relacionados 
ao Ensino Fundamental.

Apesar da dificuldade na utilização dos termos jogo e brinquedo, discutida no início deste artigo, acreditamos ser relevante que autores de trabalhos de pesquisa sobre atividades lúdicas na Educação em Ciências considerem as especificidades desses termos, em especial, no que se refere ao tipo de atividade que jogos e brinquedos proporcionam, pois essas podem influenciar na metodologia da pesquisa e nas análises que serão realizadas. Isso fica evidente na análise do foco principal dos trabalhos, em que constatamos que, em alguns estudos, dados que poderiam trazer à tona sutilezas do processo de aplicação das atividades lúdicas deixaram de ser considerados.

$\mathrm{Na}$ maioria dos trabalhos analisados neste estudo, as atividades lúdicas são qualificadas como interessantes, prazerosas e motivadoras, na perspectiva de que a ludicidade seja eficiente e suficiente por si só na promoção da aprendizagem em Ciências. Entretanto, os efeitos pedagógicos da realização de atividades lúdicas em sala de aula carecem de estudos mais aprofundados, pois jogos ou brincadeiras também podem gerar sentimentos de insatisfação no estudante quando o resultado da atividade lúdica for desfavorável a ele (Vigotski, 2008).

Por fim, cabe destacar que, na atualidade, realizar uma revisão de literatura não é uma tarefa fácil. $\mathrm{O}$ número de eventos e de periódicos na área de Educação em Ciências vem crescendo exponencialmente. Neste estudo trabalhamos apenas com um evento (ENPEC) e uma revista (RBPEC), vinculados por uma associação (ABRAPEC) e, mesmo com toda a facilidade dos aparatos tecnológicos, o grande volume de dados nos obrigou a definir delimitações e escolhas. Tal procedimento torna quase que inviáveis os estudos anteriormente categorizados como "estado da arte", mas abre possibilidades de outros estudos complementares. Por exemplo, o pequeno número de trabalhos referente ao segmento de ensino da Educação Infantil, apresentados na tabela 4, não pode ser considerado como indicador de que estudos sobre o jogos e brinquedos na Educação em Ciências nesse segmento de ensino sejam escassos, haja vista se tratar de um tema caro a outras áreas, como a Psicopedagogia e a Psicologia Social. Esses estudos podem estar sendo publicados em outros periódicos e em anais de outros eventos, o que aponta para a necessidade de estudos complementares em redes multidisciplinares de pesquisadores.

Esperamos que os resultados e conclusões deste trabalho incentivem mais pesquisadores a investigar atividades lúdicas na Educação em Ciências no Ensino Fundamental, com vistas a ampliar e aprofundar os conhecimentos disponíveis sobre o potencial pedagógico dessas atividades.

\section{Agradecimentos}

Agradecemos o apoio da Fapemig para a realização deste estudo. 


\section{Referências}

Almeida, J. A., Barbosa, E., \& Medeiros, A. J. G. (1997). A física dos brinquedos. In Anais I Encontro de Pesquisa em Educação em Ciências (p. 609). Águas de Lindóia, SP.

Almeida, C. M. M., Lopes, P. T. C., \& Dal-Farra, R. A. (2013). O lúdico como prática pedagógica no ensino de ciências: jogo didático sobre sistema esquelético. In Anais IX Encontro de Pesquisa em Educação em Ciências (pp. 1-7). Águas de Lindóia, SP.

Anjos, J. R., \& Serrano, A. (2017). Uso de linguagem de programação e atividades lúdicas como suporte para o ensino do conceito de gravidade no ensino fundamental. In Anais XI Encontro de Pesquisa em Educação em Ciências (pp. 1-8). Florianópolis, SC.

Bardi, J., \& Campos, L. M. L. (2005). Orientação sexual na séries iniciais do ensino fundamental. In Anais V Encontro de Pesquisa em Educação em Ciências (pp. 1-12). Bauru, SP.

Benjamin, W. (2009). Reflexões sobre a criança, o brinquedo e a educação (2a ed.). São Paulo, SP: Duas Cidades.

Brougère, G. (2001). Brinquedo e Cultura. São Paulo, SP: Cortez.

Cavalcanti, K. M. P. H. Guimarães, C. C., Barbosa, E. L.C. M., \& Sério, S. S. (2013). Ludo Químico: um jogo educativo para o ensino de química e física. In Anais IX Encontro de Pesquisa em Educação em Ciências (pp. 1-8). Águas de Lindóia, SP.

Chaves, A., \& Shellard, R. C. (2005). Pensando o futuro: O desenvolvimento da física e sua inserção na vida social e econômica do país. São Paulo: Sociedade Brasileira de Física.

Creswell, J. W. (2014). Investigação qualitativa e projeto de pesquisa. Porto Alegre: Penso.

Damasceno, M. T. S., \& Marin, Y. A. O. (2017). O jogo como ferramenta para o ensino e motivador da aprendizagem de conceitos associados ao tema citologia no Ensino Fundamental. In Anais XI Encontro de Pesquisa em Educação em Ciências (pp. 1-9). Florianópolis, SC.

Eiras, W. C. S. (2017). A brincadeira na educação em ciências no ensino fundamental: uma revisão bibliográfica. In Anais XI Encontro de Pesquisa em Educação em Ciências (pp. 1-10). Florianópolis, SC.

Eiras, W. C. S., \& Menezes, P. H. D. (2015). Capacitação e prática docente no ensino de ciências nos anos iniciais do ensino fundamental: uma relação necessária. In Anais $X$ Encontro de Pesquisa em Educação em Ciências (pp. 1-8). Águas de Lindóia, SP.

Ferreira, C. P., \& Meirelles, R. M. S. (2015). Avaliação da metodologia participativa na elaboração de um jogo: uma forma de trabalhar com a transversalidade construindo conhecimento e contribuindo para a promoção da saúde. (2015). Revista Brasileira de Pesquisa em Educação em Ciências. 15 (2), pp. 275-292. 
Ferreira, C. P., \& Meirelles, R. M. S. (2007). Elaboração de atividade lúdica relacionada ao tema água e saúde com a metodologia participativa. In Anais VI Encontro de Pesquisa em Educação em Ciências (pp. 1-12). Florianópolis, SC.

Figueiredo, A. F., Neto, Gomes, A. A., Augusta, B. G., Mamede, R. F. S., Rodrigues, J., \& Friolani, P. (2011). Brinca Ciência: Um Ensaio Lúdico Educativo Sobre Ciência e Tecnologia na Escola Pública do Município de Santo André. In Anais VIII Encontro de Pesquisa em Educação em Ciências (pp. 1-12). Campinas, SP.

Faria, R. L., \& Schuvartz, M. (2011).Possibilidades lúdicas em um espaço de educação não formal. In Anais VIII Encontro de Pesquisa em Educação em Ciências (pp. 1-12). Campinas, SP.

Fontoura, M. T. S., Lima, R. F., Santos, A. S., \& Pereira, R. M. M. (2009). Aplicabilidade de jogos educativos com alunos do segundo segmento do ensino fundamental do Instituto de Aplicação Fernando Rodrigues da Silveira. In Anais VII Encontro de Pesquisa em Educação em Ciências (pp. 1-6). Florianópolis, SC.

Fraga, V. M., Pery, L. C., \& Nunes, W. V. (2011). Ludicidade no estudo da velocidade escalar média: uma proposta de atividade com simuladores de corrida comerciais. In Anais VIII Encontro de Pesquisa em Educação em Ciências (pp. 1-8). Campinas, SP.

Freitas, S. A., \& Andrade, A. S., Neto. (2017). Utilização do jogo Angry Birds Space para o ensino de física no ensino fundamental. In Anais XI Encontro de Pesquisa em Educação em Ciências (pp. 1-9). Florianópolis, SC.

Garcia, L. F. C., \& Nascimento, P. M. P. (2017). O jogo didático no ensino de ciências: uma análise do jogo "descobrindo o corpo humano". In Anais XI Encontro de Pesquisa em Educação em Ciências (pp. 1-11). Florianópolis, SC.

Gondin, C. M. M., \& Machado, V. M. (2015). Uma organização praxeológica: construção coletiva de um jogo sobre os ciclos biogeoquímicos. In Anais X Encontro de Pesquisa em Educação em Ciências (pp. 1-8). Águas de Lindóia, SP.

Herrera, M. P. M. (2015). O jogo como um recurso no processo de ensino e aprendizagem de biologia. In Anais X Encontro de Pesquisa em Educação em Ciências (pp. 1-8). Águas de Lindóia, SP.

Hirsh-Pasek, K., \& Golinkoff, R. M. (2008). Why play=learning. In Tremblay, R., Boivin, M., Petes R. (eds). Encyclopedia on Early Childhood Development. Recuperado de http:// www.child-encyclopedia.com/documents/Hirsh-Pasek-GolinkoffANGxp.pdf.

Huizinga, J. (2014). Homo Ludens: o jogo como elemento da cultura (8a ed.). São Paulo, SP: Perspectiva. 
Joucoski, E., Serbena, A. L., Melo, C. C., Zanon, E. K., Santos, J., Chaves, R. K.C., \& Reis, R. A. (2011). A construção dos jogos didáticos de cartas colecionáveis como instrumento de divulgação científica no programa de extensão LabMóvel. In Anais VIII Encontro de Pesquisa em Educação em Ciências (pp. 1-13). Campinas, São Paulo.

Kishimoto, T. M. (2011). Jogo e a educação infantil. In T. M. Kishimoto (Org.). Jogo, brinquedo, brincadeira e a educação. (pp. 15-48). São Paulo, SP: Cortez.

Kraetzig, S. M. M., \& Amorim, M. A. L. (2001). Investigando o jogo como recurso didático no ensino de ciências/biologia. In Anais III Encontro de Pesquisa em Educação em Ciências (p. 1). Atibaia, SP.

Magno, C. M. V., \& Almeida, A. C. P. C. (2015). Ludicidade e CTS no ensino de ciências na educação básica de ribeirinhos na Amazônia. In Anais X Encontro de Pesquisa em Educação em Ciências (pp. 1-8). Águas de Lindóia, SP.

Massoni, N. T. (2017). Projeto de pesquisa em educação: importância, elaboração e cuidados. In Moreira, M. A., \& Massoni, N. T. Pesquisa qualitativa em educação em ciências: Projetos, entrevistas, questionários, teoria fundamentada, redação científica. (pp. 25-70). São Paulo, SP: Livraria da Física.

Matos, S. A., Giusta, A. S., \& Sabino, C. V. S. (2007). Análise da eficácia do jogo dos quatis no ensino de ecologia na $5^{a}$ série do ensino fundamental. In Anais VI Encontro de Pesquisa em Educação em Ciências (pp. 1-12). Florianópolis, SC.

MEC. Ministério da Educação. (2013). Diretrizes Curriculares Nacionais Gerais da Educação Básica. Recuperado de http://portal.mec.gov.br/docman/julho-2013pdf/13677-diretrizes-educacao-basica-2013-pdf/file

Menezes, J. E., Santos, V. B., Jr., Silva, R. S., Magalhães, J. M. C., \& Xavier, M. C. S. (2007). Jogos e ciências em interdisciplinaridade na perspectiva dos temas transversais: exemplos dos puzzles com fósforos. In Anais VI Encontro de Pesquisa em Educação em Ciências (pp. 1-12). Florianópolis, SC.

Menezes, P. H. D., Mattoso, V. C., \& Miranda, L. M. (2015). Entre o lúdico e o didático: o que se aprende com brinquedos científicos. In Anais X Encontro de Pesquisa em Educação em Ciências (pp. 1-8). Águas de Lindóia, SP.

Messeder, H. S., Neto, \& Moradillo, E. F. (2013). Ludicidade na perspectiva sociocultural: contribuições para o ensino e aprendizagem dos conceitos científicos. In Anais IX Encontro de Pesquisa em Educação em Ciências (pp. 1-8). Águas de Lindóia, SP.

Moreira, L., Abreu, T. B., Leal, A. P., \& Ramos, V. M. (2011). O jogo simbólico na educação científica. In Anais VIII Encontro de Pesquisa em Educação em Ciências (pp. 1-12). Campinas, SP.

Nicácio, S. V., \& Almeida, A. G. (2017). Uso de jogo educacional no ensino de ciências: uma proposta para estimular a visão integrada dos sistemas fisiológicos humanos. In 
Anais XI Encontro de Pesquisa em Educação em Ciências (pp. 1-10). Florianópolis, SC. Oda, W. (2013). O que há de Science no Chico Science?. In Anais IX Encontro de Pesquisa em Educação em Ciências (pp. 1-8). Águas de Lindóia, SP.

Oliveira, B. J. (2007). O profeta e o cientista: jogadas da ciência em sociedade. In Anais VI Encontro de Pesquisa em Educação em Ciências (pp. 1-7). Florianópolis, SC.

Oliveira, G. P., Carvalho, S. N., \& Góes, A. C. S. (2011). Células-tronco no reparo tecidual e sua representação em jogo didático: rompendo paradigmas no ensino de biotecnologia. In Anais VIII Encontro de Pesquisa em Educação em Ciências (pp. 1-11). Campinas, SP.

Oliveira, T. F, Soares, M. S., Cunha, R. A., \& Monteiro, S. (2008). Educação e controle da esquistossomose em Sumidouro (RJ, Brasil): avaliação de um jogo no contexto escolar. Revista Brasileira de Pesquisa em Educação em Ciências. 8(3), 1-18.

Oliveira, T. F., \& Monteiro, S. (2005). Prevenção da esquistossomose no contexto escolar: avaliação de materiais educativos como uma forma de investigação (Sumidouro, RJ). In Anais V Encontro de Pesquisa em Educação em Ciências (p. 1). Bauru, SP.

Ramos, R. A., Tanaka, A, L. D., \& Anic, C. C. (2013). Tendências investigativas para o ensino de Ciências: uma proposta lúdica para o ensino da temática alimentação. In Anais IX Encontro de Pesquisa em Educação em Ciências (pp. 1-8). Águas de Lindóia, SP.

Rosse, C. G., Spiegel, C. N., \& Luz, M. R. M. P. (2015). Cooperação ou torneio? O sucesso de diferentes estratégias de ensino no jogo" fome de Q?". In Anais X Encontro de Pesquisa em Educação em Ciências (pp. 1-8). Águas de Lindóia, SP.

Santana, E. M., \& Rezende, D. B. (2007). A influência de jogos e atividades lúdicas no ensino e aprendizagem de química. In Anais VI Encontro de Pesquisa em Educação em Ciências (pp. 1-12). Florianópolis, SC.

Santos, G. S., Luz, M. R. M. P., \& Oliveira, M. F. A. (2013). Ensino em biociências e saúde: o exemplo de uma atividade lúdica sobre perfil alimentar. In Anais IX Encontro de Pesquisa em Educação em Ciências (pp. 1-8). Águas de Lindóia, SP.

Santos, G. S., \& Oliveira, M. F. (2015). Na trilha dos nutrientes: jogo didático voltado para o ensino de nutrição em turmas do $8^{\circ}$ ano do ensino fundamental. In Anais $X$ Encontro de Pesquisa em Educação em Ciências (pp. 1-8). Águas de Lindóia, SP.

Santos, J., Magalhães, V. L., \& Gois J. (2009). Uma forma lúdica de ensinar ciências para crianças do ensino fundamental. In Anais VII Encontro de Pesquisa em Educação em Ciências (1-6). Florianópolis, SC.

Silva, R. M. L., Silva, J. R. L., Mise, Y. F., Dores, J. L. R., \& Araújo, B. R. N. (2011). Ludicidade e ciência: produção e divulgação de jogos sobre ciências em um espaço de ensino não-formal. In Anais VIII Encontro de Pesquisa em Educação em Ciências (pp. 1-11). Campinas, SP. 
Silva, T. M. F., \& Mesquita, N. A. S. (2013). Formação continuada de professores de ciências na educação a distância: instrumentação por meio lúdico. In Anais IX Encontro de Pesquisa em Educação em Ciências (pp. 1-8). Águas de Lindóia, SP.

Souza, D. C., \& Nascimento, A. F., Jr. (2005). Jogos didático-pedagógicos ecológicos: uma proposta para o ensino de ciências, ecologia e educação ambiental. In Anais $V$ Encontro de Pesquisa em Educação em Ciências (pp. 1-12). Bauru, SP.

Souza, E. J., Yoshimura, M.T. S., Patrícia, P., \& Testoni, L. A. (2017). O jogo do perito: uma proposta investigativa para o ensino de ciências utilizando elementos de física forense. In Anais XI Encontro de Pesquisa em Educação em Ciências (pp. 1-10). Florianópolis, SC.

Souza, J. S., \& Rizzatti, I. M. (2017). Análise de conversas de aprendizagem estimuladas por meio do jogo experimental "Na trilha da ciência". In Anais XI Encontro de Pesquisa em Educação em Ciências (pp. 1-8). Florianópolis, SC.

Veraszto, E. V., Silva, D., Yamamoto, A. C. I., Simon, F. O., Miranda, N. A., \& Cunha, A. M. (2005). Uma alternativa para alfabetização tecnológica desde as séries iniciais do ensino fundamental. In Anais V Encontro de Pesquisa em Educação em Ciências (pp. 1-12). Bauru, SP.

Vigotski, L. S. (2008, Junho). A brincadeira e o desenvolvimento psíquico da criança. (Prestes, Z., Trad.). Revista Virtual de Gestão de Iniciativas Sociais, (8), 23-36. Recuperado de https://isabeladominici.files.wordpress.com/2014/07/revista-educ-infant-indic-zoia. pdf

Vigotski, L. S. (2000). A formação social da mente (6ª ed.). São Paulo: Martins Fontes. 
Wagner da Cruz Seabra Eiras

${ }^{1}$ http://orcid.org/0000-0002-3879-3638 Instituto Federal do Sudeste de Minas Gerais

Departamento de Educação em Ciências Juiz de Fora, Brasil wagner.seabra@ifsudestemg.edu.br

Paulo Henrique Dias Menezes

${ }^{0}$ http://orcid.org/0000-0002-3008-9830 Universidade Federal de Juiz de Fora Faculdade de Educação Juiz de Fora, Brasil paulo.menezes@ufjf.edu.br

\section{Cristhiane Carneiro Cunha Flôr}

http://orcid.org/0000-0002-9175-1859 Universidade Federal de Juiz de Fora Faculdade de Educação Juiz de Fora, Brasil criscunhaflor@gmail.com

Submetido em 25 de Outubro de 2017 Aceito em 13 de Dezembro de 2017 Publicado em 21 de Abril de 2018 